Tropical Journal of Pharmaceutical Research September 2014; 13 (9): 1477-1485

ISSN: $1596-5996$ (print); 1596-9827 (electronic)

(c) Pharmacotherapy Group, Faculty of Pharmacy, University of Benin, Benin City, 300001 Nigeria.

All rights reserved.

Available online at http://www.tjpr.org

Original Research Article

http://dx.doi.org/10.4314/tjpr.v13i9.14

\title{
Evaluation of the Antioxidant Activities of Ya-hom Intajak, a Thai Herbal Formulation, and its Component Plants
}

\author{
Jantanarak Tuekaew ${ }^{1}$, Nisarat Siriwatanametanon ${ }^{1}$, Yuvadee Wongkrajang ${ }^{2}$, \\ Rungravi Temsiririrkkul ${ }^{1}$ and Ibrahim Jantan ${ }^{3 *}$ \\ ${ }^{1}$ Department of Pharmaceutical Botany, ${ }^{2}$ Department of Physiology, Faculty of Pharmacy, Mahidol University, 447 Sri-Ayuthaya \\ Road, Rajathevi, Bangkok, 10400, Thailand, ${ }^{3}$ Drug and Herbal Research Centre, Faculty of Pharmacy, Universiti Kebangsaan, \\ Jalan Raja Muda Abdul Aziz, 50300 Kuala Lumpur, Malaysia
}

*For correspondence: Email: profibj@gmail.com; Tel: +603 92897315; Fax: +60326983271

Received: 25 February 2014

Revised accepted: 3 August 2014

\begin{abstract}
Purpose: To evaluate the antioxidant effect of $80 \%$ ethanol extract and its $n$-hexane and dichloromethane fractions of Ya-hom Intajak, and its 47 medicinal plants components.

Methods: The $80 \%$ ethanol extract and its n-hexane and dichloromethane fractions were investigated on human low-density lipoprotein (LDL) peroxidation by thiobarbituric acid reactive substances (TBARS) assay. Antioxidant effect was also determined by 2,2-diphenyl-1-picrylhydrazyl (DPPH) radical scavenging capacity and ferric reducing antioxidant power (FRAP) assays.

Results: The extract of Ya-hom Intajak exhibited moderate DPPH scavenging activity with an $I C_{50}$ value of $99.08 \mu \mathrm{g} / \mathrm{ml}$ and a FRAP value of $1.12 \mathrm{mmol} \mathrm{FeSO} / \mathrm{g}$. Among the individual plants, Terminalia chebula Retz., Caesalpinia sappan L., Cinnamomum bejolghota (Buch.-Ham.) and Ci. verum J. Presl, showed strong antioxidant activities. T. chebula was the most potent plant in the DPPH assay while Ca. sappan had the highest FRAP value. Among the extracts, the dichloromethane fraction showed the highest inhibitory effect on $L D L$ peroxidation with a half maximal inhibitory concentration $\left({ }^{\prime} C_{50}\right)$ value comparable to that of probucol $(0.82 \mu \mathrm{g} / \mathrm{ml})$. Pearson correlation analysis revealed that total phenolic content (TPC) showed high positive correlations with FRAP $(r=0.908, p<0.01)$ and DPPH activities $(r$ $=0.648, p<0.01)$.

Conclusion: Ya-hom Intajak is a valuable source of natural antioxidants and has a potential application as a cardiovascular protective formulation.
\end{abstract}

Keywords: Ya-hom Intajak, Antioxidant activity, Terminalia chebula Retz., Caesalpinia sappan L., Cinnamomum bejolghota (Buch.-Ham.), Ci. verum J. Presl, Phenolic content

Tropical Journal of Pharmaceutical Research is indexed by Science Citation Index (SciSearch), Scopus, International Pharmaceutical Abstract, Chemical Abstracts, Embase, Index Copernicus, EBSCO, African Index Medicus, JournalSeek, Journal Citation Reports/Science Edition, Directory of Open Access Journals (DOAJ), African Journal Online, Bioline International, Open-J-Gate and Pharmacy Abstracts

\section{INTRODUCTION}

The initiation and progression of early stage of atherosclerosis and the development of cardiovascular diseases have been attributed to the oxidation of low-density lipoproteins (LDL). Reduction of LDL oxidation may be one of the most important therapeutic approaches to prevent the development of atherosclerosis.
Many antioxidants have been developed to delay or inhibit the oxidation of the biomolecules by terminating the initiation or propagation of the oxidizing chain reactions by free radicals and inhibiting the foam cell formation [1]. The antioxidant activity of phenolic compounds is mainly due to their redox properties, which play an important role in adsorbing and neutralizing free radicals, quenching singlet and triplet 
oxygen or decomposing peroxides [2]. Many studies have indicated that there was a high correlation between the antioxidant activity of some plants and their phenolic contents [3-5]. The bioactive components can effectively inhibit LDL oxidation and may prevent atherosclerosis by reducing and slowing down the progression to advance stage [5].

Ya-hom is a traditional herbal formulation used widely in Thailand for the treatment of nausea, vomiting, dizziness and fainting, especially among the aged population. It is also used as a cardiotonic agent and tonic for longevity. There are many preparations of Ya-hom with most formula contain similar major ingredients but different total composition and amounts of medicinal plants [6]. There have been reports on the effects of Ya-hom on both animal and human cardiovascular function. The effect of Ya-hom on the pulse rate and pulse pressure in human has been reported [7]. The effect of the herbal preparation on blood pressure in rats and in isolated rat aortic ring and atrium have also been investigated [8-10]. However, the results obtained by the different studies were not in agreement and remain inconclusive, most probably due to the use of different Ya-hom formula, extraction methods and experimental models. Among those Ya-hom preparations, Yahom Intajak was listed by the National Drug Committee (Thailand) in the List of Herbal Medicine Products A.D. 2011 and declared as over the counter herbal drug. Ya-hom Inthajak is also accepted to be used as cardiotonic agent and also improving blood circulation [11]. The aim of this study was to evaluate the antioxidant effect of Ya-hom Intajak against human LDL oxidation, radical scavenging activity against 2,2diphenyl-1-picrylhydrazyl (DPPH) and ferric reducing antioxidant power (FRAP). The relationships between these activities and their total phenolic contents and total flavonoid content were also established.

\section{EXPERIMENTAL}

\section{Preparation of extracts}

Yahum Intajak used in this study contained 47 single component plants as listed in Tables 1(a) and $1(\mathrm{~b})$. The single medicinal plant components of the herbal formulation were purchased from Jaokrompur, a herbal drug store in Bangkok, Thailand and their identities were confirmed by Dr Wongsatit Chuakul of Mahidol University, Thailand. Ya-hom Intajak formula was prepared by mixing and grinding equal amount of each of the 47 component herbs, according to the formulatory provided by the List of Herbal Medicines Products A.D. 2011 [11]. The powdered mixture $(100 \mathrm{~g})$ was extracted with $2,000 \mathrm{ml}$ of $80 \%$ ethanol using a percolator and then the ethanol extract was successfully fractionated with n-hexane, dichloromethane and $80 \%$ ethanol. Each plant was dried in a hot air oven at $50{ }^{\circ} \mathrm{C}$, ground and then $30 \mathrm{~g}$ of the powder was macerated with $600 \mathrm{ml}$ of $80 \%$ ethanol. The extract was filtered through Whatman filter paper No.1 and the entire extraction process was repeated thrice on the marc. The extracts and filtrates were concentrated under reduced pressure.

\section{Determination of DPPH radical scavenging activity}

DPPH scavenging activity of the extracts was carried out according to the method described by Kordali et al with slight modification [12]. Briefly, $2 \mathrm{ml}$ of each extract at various concentrations $(100,80,60,40$ and $20 \mu \mathrm{g} / \mathrm{\mu l})$ were respectively added to $2 \mathrm{ml}$ of freshly prepared DPPH methanol solution $(4 \mathrm{mg} / 100 \mathrm{ml})$. The mixtures were vortexed vigorously with a votex mixer and allowed to stand in the dark for $30 \mathrm{~min}$ at room temperature for any radical-antioxidant reaction to occur. Finally, the absorbance of these mixtures was measured by using a Shimadzu UV-1800 spectrophotometer (Shimadzu, Kyoto, Japan) at $517 \mathrm{~nm}$. The difference in absorbance between the sample and the control was calculated as percentage (\%) inhibition of DPPH activity. The $\mathrm{IC}_{50}$ values, i.e. concentration of sample providing $50 \%$ of radical scavenging activity was obtained through interpolation of linear regression analysis. Ascorbic acid in methanol was used as a positive control and the assay was conducted in triplicate for each sample concentration.

\section{Ferric reducing ability power assay (FRAP)}

The FRAP assay was performed according to the procedure described by Benzie and Szeto [13]. The FRAP reagent was prepared from $300 \mathrm{mM}$ sodium acetate buffer ( $\mathrm{pH}$ 3.6), $10 \mathrm{mM}$ TPTZ dissolved by $40 \mathrm{mM} \mathrm{HCl}$ and $20 \mathrm{mM}$ ferric chloride in the volume ratio of 10:1:1. The different concentrations $(400-800 \mu \mathrm{g} / \mathrm{ml})$ of sample was dissolved using methanol as a solvent. $25 \mu \mathrm{l}$ of each concentration of the sample was added to $175 \mu$ l of FRAP reagent. Blank experiment contained $25 \mu \mathrm{l}$ of sample and $175 \mu \mathrm{l}$ of sodium acetate buffer. The absorbance of the mixtures was measured at $593 \mathrm{~nm}$ using UV- spectrophotometer (DKSH). Ascorbic acid in methanol was used as a positive control and the 
experiment was conducted in triplicate. The standard curve was plotted using $\mathrm{FeSO}_{4}$ solutions and the result is expressed as $\mathrm{mM}$ of $\mathrm{FeSO}_{4}$ equivalents.

\section{Evaluation of inhibitory effect on human low density lipoprotein peroxidation}

The assay was performed following the method of Dillon with slight modification [14]. The procedure included LDL isolation, LDL oxidation and TBARS assay. The use of human whole blood in this study was approved by the Ethics Committee of the Universiti Kebangsaan Malaysia (approval no. FF-120-2007), following the International Ethical Guidelines for Biomedical Research Involving Human Subjects (CIOMS and WHO) [15]. Whole blood was drawn from the vein of healthy volunteers aged between 24 and 70 years who were normolipidemic, nonsmoking, had not taken any medications and supplements within the last two weeks and also claimed they fasted for $8 \mathrm{~h}$, prior to blood withdrawal.

For LDL isolation, $9 \mathrm{ml}$ of the blood was added into $1 \mathrm{ml}$ of $3.8 \%(\mathrm{w} / \mathrm{v})$ sodium citrate (Merck, Darmstadt, Germany) solution as an anticoagulant, then centrifuged at $2,000 \mathrm{~g}$ for 20 min to separate plasma. The plasma $(3.2 \mathrm{ml})$ was mixed well with $0.8 \mathrm{ml}$ of OptiprepTM $(60 \%$ iodixanol) (Sigma Chemical Co.) as the density gradient medium to give a final iodixanol concentration of $12 \%(\mathrm{v} / \mathrm{v})$. This mixture was added in to $8.9 \mathrm{ml}$ OptisealTM tube, then carefully added $4 \mathrm{ml}$ of $6 \%$ iodixanol in saline, after that topped up with $0.9 \mathrm{ml}$ of saline. The tube was ultracentrifuged at 402,000 times gravity $(\mathrm{g}), 16^{\circ} \mathrm{C}$ for $3 \mathrm{~h} 10 \mathrm{~min}$ using the Ti.70.1 rotor. The subfractions of lipoprotein: highdensity lipoprotein $(\mathrm{HDL})$, low-density lipoprotein (LDL) and very low-density lipoprotein (VLDL) was obtained. LDL was characterized by measuring the amount of protein by using Bovine serum albumin (Protein kit Sigma Chemical Co.) as a standard. The purity of LDL was measured by using electrophoresis. Agarose gel (Bio-Rad, USA) was used as solid support in electrophoresis. Samples were electrophoresed at a constant $45 \mathrm{~mA} / \mathrm{gel}$ for $45 \mathrm{~min}$, then oven dried at $85^{\circ} \mathrm{C}$ for $20 \mathrm{~min}$ and stained with Sudan Black (Sigma,USA). The band was visually observed under UV detector. Then, LDL was diluted with phosphate buffer saline (PBS) $(\mathrm{pH}$ 7.4) to a final concentration of $200 \mu \mathrm{g}$ protein $/ \mathrm{ml}$ before oxidation testing.

For oxidation of LDL, the reaction was initiated by adding freshly prepared $10 \mu \mathrm{M} \mathrm{CuSO}_{4}$ (Sigma, USA) solution. The samples were dissolved in DMSO to obtain serial concentrations of $1.25,0.63,0.31,0.16$ and 0.08 $\mu \mathrm{g} / \mu \mathrm{l}$. Five $\mu \mathrm{l}$ of the samples were added to a cuvete containing $945 \mu \mathrm{l}$ of LDL, $50 \mu \mathrm{l}$ of $10 \mu \mathrm{M}$ $\mathrm{CuSO}_{4}$ and incubated at $37^{\circ} \mathrm{C}$ for $5 \mathrm{~h}$. The final concentrations of the extracts in the mixture were $6.25,3.13,1.56,0.78$ and $0.39 \mu \mathrm{g} / \mathrm{ml}$. $0.5 \%$ DMSO was used as control and blank while probucol (Sigma, USA) was used as the positive control. The oxidation of LDL was terminated by rapid freezing and kept at $-20{ }^{\circ} \mathrm{C}$ with no longer than $24 \mathrm{~h}$.

For thiobarbituric reactive substances (TBARS) assay, $100 \mu \mathrm{l}$ of sodium dodecyl sulphate (SDS) (Zeptometrix Co., USA) and $2.5 \mathrm{ml}$ of thiobarbituric acid (TBA) (Zeptometrix Co., USA) were added to the mixture. Then, it was incubated at $95{ }^{\circ} \mathrm{C}$ for $1 \mathrm{~h}$ to promote peroxidation. The mixture was put on ice for 10 min to cool down and stop the peroxidation process. The precipitate formed was removed by centrifugation at $3000 \mathrm{rpm}, 15 \mathrm{~min}$. The absorbance was measured at $532 \mathrm{~nm}$. Then, the malondialdehyde (MDA) in the supernatant was calculated and expressed as nmoles of MDA $/ \mathrm{mg}$ LDL protein. Standard MDA was used as a reference and plotted the standard curve.

\section{Determination of total phenolic content}

The total phenolic content (TPC) of extract was determined using the Folin-Ciocalteau method with some modification [16]. Briefly, $33 \mu \mathrm{l}$ of each sample was mixed with $83 \mu \mathrm{l}$ of FolinCiocalteau reagent (Sigma, USA) which was diluted (1:10) with water. Then $133 \mu$ of $7.5 \%$ $\mathrm{w} / \mathrm{v}$ sodium bicarbonate was added in to the mixture. The absorbance of the mixture was measured at $765 \mathrm{~nm}$ after for 30 min standing at room temperature. Gallic acid $(5-35 \mu \mathrm{g} / \mathrm{ml})$ (Sigma, USA) was used as standard and plotted standard curve. The total phenolic content was reported as gallic acid equivalents (GAE) per gram of sample.

\section{Determination of total flavonoid content}

The total flavonoid content (TFC) was determined using the Dowd method [17]. Briefly, $100 \mu \mathrm{l}$ of $2 \% \mathrm{AlCl}_{3}$ in methanol was mixed with $100 \mu \mathrm{l}$ of the sample solution. The absorbance of the mixture was measured at $415 \mathrm{~nm}$ using Pelkin Elmer UV-VIS lambda 25 spectrophotometer after 10 min against a blank sample consisting of methanol. The TFC was determined using a standard curve of quercetin $(5-30 \mu \mathrm{g} / \mathrm{ml})$. The mean of three readings was used and expressed as milligrams of quercetin equivalents $(\mathrm{QE}) / \mathrm{l} \mathrm{g}$ of extract. 


\section{Statistical analysis}

All the data are presented as standard error of the mean $\pm(\mathrm{SEM})$ from triplicate experiments and were analysed using Statistically Package for Social Sciences (SPSS) software version 17.0. A one-way analysis of variance (ANOVA) was used for multiple comparison. The concentration of the compounds required to inhibit $50 \%$ oxidation $\left(\mathrm{IC}_{50}\right)$ for active extract was determined using probit programme. The correlation between TPC and TFC in the extracts and antioxidant properties was described by the Pearson product-movement correlation coefficient $(r) . P<0.05$ was considered to be statistically significant.

\section{RESULTS}

In this study, DPPH radical scavenging capacity and FRAP have been used to evaluate antioxidant activity of the ethanol extract of Yahom Intajak and its fraction together with 47 medicinal plants contained in the Ya-hom formula. The samples were evaluated for their radical scavenging capacity using DPPH assay which is based on the scavenging of the stable $\mathrm{DPPH} \cdot$ by an antioxidant. Tables 1(a) and 1(b) show the $\mathrm{IC}_{50}$ values of $\mathrm{DPPH}$ scavenging activity of the ethanol extract of Ya-hom and its fractions and the single plants. The FRAP assay was used to investigate antioxidant activity which is based on the capacity of antioxidants to reduce ferric ions to ferrous ions. The FRAP values (mmol Fe (II) $/ 1 \mathrm{~g}$ dried extract) of the ethanol extract of Ya-hom and its fractions and the single plants are shown in Table 1(a) and (b).

The TPC and TFC of the extracts were determined and their values varied considerably, ranging from 6.73 to $268.11 \mathrm{mg}$ gallic acid equivalents per gram (mg GAE/g) and from 0.80 to $87.33 \mathrm{mg} \mathrm{QE} / \mathrm{g}$, respectively [Tables 1 (a) and (b)]. Statistical correlations have been studied between TPC and TFC of the extracts of the 47 plants and their DPPH scavenging capacity and FRAP. To access the degree and the direction of the linear relationship between TPC, TFC and antioxidant activity, a bivariate Pearson's product-movement correlation coefficient $(r)$ was calculated. The Pearson correlation analysis indicates that the DPPH assay showed positive correlation with TPC $(r=0.647, p<0.01)$ and TFC $(r=0.285, p<0.05)$ and the FRAP assay showed strong positive correlation with both phenolic contents $(r=0.908, p<0.01)$ and flavonoid contents $(r=0.508, p<0.01)$. The high correlation between the antioxidant activity and their TPC and TFC indicated that phenolic compounds might be a major contributor of antioxidant activities of these plants.

The ethanol extract of Ya-hom Intajak and its fractions were also investigated for their ability to inhibit copper-mediated oxidation on isolated human LDL. The human LDL was isolated by ultracentrifugation method and its purity was evaluated by using UV spectrophotometer and agarose gel electrophoresis. LDL was incubated with copper ions which catalyzed a lipid peroxidation process, in the presence or absence (negative control) of each of the extract. The level of in vitro oxidative modification of LDL oxidation was measured quantitatively by the TBARS method based on malondialdehyde (MDA) production. Probucol was used as the positive control. The inhibitory effect $\left(\mathrm{IC}_{50}\right)$ of the extracts on LDL oxidation are shown in Table 2.

\section{DISCUSSION}

The antioxidant activity of botanical materials has been measured by various methods such as DPPH radical scavenging activity assay, ABTS radical cation scavenging activity assay, superoxide anion radical scavenging activity assay, oxygen radical absorbance capacity (ORAC) assay, ferric reducing/antioxidant power (FRAP) assay and metal chelating activity assay. The need to use different methods of antioxidant capacity measurement is due to these various mechanisms of antioxidant action. Determination of the antioxidant activity of plant extracts and compounds often gave different results as the methods used are based on different reaction mechanisms [18].

The ethanol extract of Ya-hom showed moderate DPPH scavenging activity $(99.08 \mu \mathrm{g} / \mathrm{ml})$. The $I_{50}$ values of the 47 single plants ranged from 15.35 to $1261.84 \mu \mathrm{g} / \mathrm{ml}$ with a difference of $83-$ fold between the least and most active extract. Of all the plants tested, ten plants showed greater DPPH scavenging activity than the whole Ya-hom formula, and Terminalia chebula was the most potent with $\mathrm{IC}_{50}$ value $(15.35 \mu \mathrm{g} / \mathrm{ml})$, comparable to that of ascorbic acid, the positive control used. In a previous study, gallic acid from the gall of $T$. chebula has showed in vitro antiaging activities on DPPH radical scavenging and stimulation index on normal human fibroblast proliferation [19]. 
Table 1: FRAP values (mmol FeSO4/g dried extract) and $\mathrm{IC}_{50}$ values $(\mu \mathrm{g} / \mathrm{ml})$ of the ethanol extract of Ya-hom Intajak and its fractions and 47 of its plant constituents on DPPH radical scavenging activity, their total contents of phenolic and flavonoid (mg QE/g) and their percentage (\%) yields of extracts

\begin{tabular}{|c|c|c|c|c|c|}
\hline Sample & $\begin{array}{l}\text { DPPH radical } \\
\text { scavenging activity } \\
\text { IC }_{50} \text { value }(\mu \mathrm{g} / \mathrm{ml})\end{array}$ & $\begin{array}{l}\text { FRAP value } \\
\left(\mathrm{mmol} \mathrm{FeSO}_{4} / \mathrm{g}\right)\end{array}$ & $\begin{array}{l}\text { Total phenolic } \\
\text { content } \\
\text { (mg GAE/g) }\end{array}$ & $\begin{array}{l}\text { Total flavonoid } \\
\text { content } \\
\text { (mg QE/g) }\end{array}$ & $\begin{array}{l}\text { Extract yield } \\
(\% w / w)\end{array}$ \\
\hline Ya-hom Formula extract & $99.08 \pm 8.77$ & $0.93 \pm 0.12$ & $51.67 \pm 1.87$ & $8.41 \pm 0.36$ & 22.50 \\
\hline Ethanol Fraction & $145.5 \pm 6.71$ & $0.81 \pm 0.12$ & $112.35 \pm 6.08$ & $13.18 \pm 1.00$ & 13.95 \\
\hline Dichloromethane Fraction & $154.25 \pm 7.15$ & $0.76 \pm 0.08$ & $112.61 \pm 5.39$ & $1.37 \pm 0.09$ & 2.88 \\
\hline Hexane Fraction & $303.73 \pm 31.34$ & $0.65 \pm 0.09$ & $48.75 \pm 4.41$ & $10.13 \pm 0.90$ & 4.06 \\
\hline Alyxia reinwardtii Blume & $>500$ & $0.49 \pm 0.02$ & $27.33 \pm 1.21$ & $1.37 \pm 0.09$ & 9.17 \\
\hline Amomum testaceum Ridl. & $263.93 \pm 11.72$ & $0.53 \pm 0.09$ & $49.44 \pm 7.16$ & $3.93 \pm 1.00$ & 2.50 \\
\hline Anacyclus pyrethrum (L.) Lagasca & $300.45 \pm 7.51$ & $0.48 \pm 0.02$ & $42.21 \pm 1.59$ & $7.74 \pm 0.18$ & 4.34 \\
\hline Angelica dahurica Benth. & $>500$ & $0.29 \pm 0.02$ & $24.31 \pm 0.38$ & $1.24 \pm 0.15$ & 9.46 \\
\hline Angelica sinensis (Oliv.) Diels & $>500$ & $0.22 \pm 0.01$ & $13.34 \pm 1.05$ & $1.20 \pm 0.07$ & 30.93 \\
\hline Aquilaria gallocha Roxb. & $318.24 \pm 14.10$ & $0.69 \pm 0.16$ & $49.92 \pm 4.75$ & $13.06 \pm 0.71$ & 3.08 \\
\hline Aristolochia pierrei & $453.48 \pm 29.38$ & $0.79 \pm 0.02$ & $32.59 \pm 1.47$ & $16.20 \pm 0.92$ & 2.21 \\
\hline Artemisia annua $\mathrm{L}$. & $462.52 \pm 24.15$ & $0.32 \pm 0.01$ & $36.93 \pm 0.78$ & $36.73 \pm 0.16$ & 14.41 \\
\hline Atractylodes lancea (Thung.) DC. & $>500$ & $0.32 \pm 0.02$ & $19.63 \pm 10.00$ & $2.77 \pm 0.08$ & 10.89 \\
\hline Bixa orellana L. & $61.63 \pm 5.19$ & $1.08 \pm 0.05$ & $128.29 \pm 5.45$ & $24.75 \pm 1.90$ & 14.59 \\
\hline Caesalpinia sappan $\mathrm{L}$. & $32.37 \pm 1.25$ & $2.77 \pm 0.10$ & $247.83 \pm 7.98$ & $75.18 \pm 2.39$ & 7.34 \\
\hline Cananga odorata (Lam.) Hook. f \& & $327.39 \pm 20.68$ & $0.40 \pm 0.04$ & $30.67 \pm 0.83$ & $17.79 \pm 1.48$ & 28.02 \\
\hline Thomson var. odorata & - & - & - & - & - \\
\hline Cinnamomum bejolghota (Buch.-Ham.) & $20.04 \pm 0.75$ & $2.30 \pm 0.21$ & $247.21 \pm 6.46$ & $8.46 \pm 0.44$ & 27.96 \\
\hline Cinnamomum verum J. Presl & $38.5 \pm 2.24$ & $1.93 \pm 0.24$ & $144.65 \pm 5.86$ & $13.26 \pm 1.98$ & 23.39 \\
\hline Coriandrum sativumL. & $>500$ & $0.23 \pm 0.03$ & $16.82 \pm 1.45$ & $1.86 \pm 0.10$ & 7.11 \\
\hline Cuminum cyminum $\mathrm{L}$. & $419.86 \pm 18.88$ & $0.25 \pm 0.04$ & $24.97 \pm 1.28$ & $40.37 \pm 3.68$ & 13.85 \\
\hline Dracaena loureiri Gagnep. & $149.85 \pm 10.90$ & $0.36 \pm 0.38$ & $68.17 \pm 2.7$ & $25.17 \pm 0.66$ & 12.93 \\
\hline Enhalus acoroides (L.f.) Royle & $484.09 \pm 14.20$ & $0.35 \pm 0.06$ & $22.61 \pm 0.15$ & $14.43 \pm 1.17$ & 5.57 \\
\hline Euphorbia antiquorum L. & $>500$ & $0.36 \pm 0.03$ & $29.59 \pm 2.55$ & $2.09 \pm 0.07$ & 7.52 \\
\hline Foeniculum vulgare Mill. var dulce Alef & $>500$ & $0.18 \pm 0.05$ & $24.02 \pm 3.1$ & $10.57 \pm 0.23$ & 8.57 \\
\hline Gymnopetalum chinense (Lour.) Merr. & $>500$ & $0.21 \pm 0.03$ & $6.87 \pm 0.96$ & $3.10 \pm 0.54$ & 12.20 \\
\hline Jasminum sambac (L.) Aiton & $>500$ & $0.25 \pm 0.03$ & $21.51 \pm 1.3$ & $22.71 \pm 0.58$ & 20.69 \\
\hline Lepidium sativum $\mathrm{L}$. & $355.73 \pm 12.72$ & $0.62 \pm 0.02$ & $39.34 \pm 2.17$ & $13.30 \pm 0.87$ & 12.06 \\
\hline Mammea siamensis & $220.89 \pm 6.85$ & $0.55 \pm 0.01$ & $50.58 \pm 5.3$ & $13.90 \pm 0.30$ & 20.59 \\
\hline Mesua ferrea $L$. & $121.611 \pm 11.62$ & $0.65 \pm 0.03$ & $46.78 \pm 2.2$ & $13.58 \pm 0.34$ & 19.63 \\
\hline Michelia champaca L. & $139.75 \pm 3.10$ & $0.77 \pm 0.08$ & $77.39 \pm 0.75$ & $13.45 \pm 0.60$ & 11.51 \\
\hline Mimusops elengi L. (Flower) & $146.56 \pm 4.32$ & $0.53 \pm 0.05$ & $54.51 \pm 1.54$ & $6.07 \pm 0.25$ & 19.04 \\
\hline
\end{tabular}


Table 1 (continued): FRAP values (mmol FeSO4/g dried extract) and $\mathrm{IC}_{50}$ values $(\mu \mathrm{g} / \mathrm{ml}$ ) of the ethanol extract of Ya-hom Intajak and its fractions and 47 of its plant constituents on DPPH radical scavenging activity, their total contents of phenolic and flavonoid (mg QE/g) and their percentage (\%) yields of extracts

\begin{tabular}{|c|c|c|c|c|c|}
\hline Sample & $\begin{array}{l}\text { DPPH radical } \\
\text { scavenging activity } \\
\text { IC }_{50} \text { value }(\mu \mathrm{g} / \mathrm{ml})\end{array}$ & $\begin{array}{l}\text { FRAP value } \\
\left(\mathrm{mmol} \mathrm{FeSO}_{4} / \mathrm{g}\right)\end{array}$ & $\begin{array}{l}\text { Total phenolic } \\
\text { content } \\
\text { (mg GAE/g) }\end{array}$ & $\begin{array}{l}\text { Total flavonoid } \\
\text { content } \\
\text { (mg QE/g) }\end{array}$ & $\begin{array}{l}\text { Extract yield } \\
(\% w / w)\end{array}$ \\
\hline Mimusops elengi L. (Infected wood) & $>500$ & $0.37 \pm 0.05$ & $27.84 \pm 0.22$ & $6.13 \pm 0.48$ & 4.95 \\
\hline Myristica fragransHoutt. (Aril) & $49.78 \pm 2.76$ & $0.73 \pm 1.03$ & $81.26 \pm 2.41$ & $0.80 \pm 1.07$ & 17.47 \\
\hline Myristica fragransHoutt. (Seed) & $115.13 \pm 0.53$ & $0.50 \pm 0.63$ & $67.03 \pm 9.3$ & $4.12 \pm 0.09$ & 11.78 \\
\hline Nigella sativa $\mathrm{L}$. & $>500$ & $0.25 \pm 0.05$ & $6.73 \pm 0.51$ & $1.97 \pm 0.05$ & 15.65 \\
\hline Picrorhiza kurrooa Royle ex Benth. & $348.77 \pm 13.37$ & $0.44 \pm 0.03$ & $49.72 \pm 4.5$ & $25.35 \pm 0.53$ & 23.55 \\
\hline Piper retrofractum Vahl & $>500$ & $0.26 \pm 0.01$ & $18.18 \pm 1.09$ & $4.26 \pm 0.22$ & 15.89 \\
\hline Piper ribesoides Wall. & $143.46 \pm 10.07$ & $1.05 \pm 0.06$ & $59.22 \pm 1.51$ & $3.38 \pm 0.30$ & 6.59 \\
\hline Piper sarmentosum Roxb. & $>500$ & $0.27 \pm 0.01$ & $22.01 \pm 0.78$ & $15.17 \pm 0.77$ & 12.36 \\
\hline Plumbago indica L. & $273.01 \pm 20.69$ & $0.47 \pm 0.05$ & $29.77 \pm 1.59$ & $3.64 \pm 0.21$ & 23.57 \\
\hline Rheum palmatum $\mathrm{L}$. & $81.82 \pm 5.54$ & $1.60 \pm 0.11$ & $151.17 \pm 5.05$ & $10.78 \pm 2.3$ & 31.42 \\
\hline Santalum album $\mathrm{L}$. & $240.38 \pm 3.91$ & $0.35 \pm 0.36$ & $48.79 \pm 1.18$ & $7.29 \pm 0.66$ & 5.56 \\
\hline Saussurea lappa C.B.Clarke & $499.48 \pm 22.29$ & $0.38 \pm 0.06$ & $31.17 \pm 1.78$ & $4.73 \pm 0.26$ & 28.59 \\
\hline Syzygium aromaticum (L.) & $37.36 \pm 3.55$ & $2.66 \pm 0.18$ & $201.38 \pm 5.65$ & $15.00 \pm 0.22$ & 26.11 \\
\hline Terminalia chebula Retz. & $15.35 \pm 0.8$ & $2.72 \pm 0.08$ & $268.11 \pm 0.58$ & $87.33 \pm 2.57$ & 10.39 \\
\hline Tiliacora triandra (Colebr.) Diels & $141.56 \pm 12.2$ & $1.07 \pm 0.09$ & $75.86 \pm 5.46$ & $6.91 \pm 0.38$ & 8.93 \\
\hline Tinospora crispa (L.) Miers & $383.16 \pm 17.03$ & $0.51 \pm 0.06$ & $29.83 \pm 2.14$ & $4.52 \pm 0.49$ & 12.81 \\
\hline Trachyspermum ammi (L.) Sprague & $221.48 \pm 18.58$ & $0.43 \pm 0.41$ & $69.74 \pm 1.25$ & $30.42 \pm 0.80$ & 10.68 \\
\hline Urceola minutiflora (Pierre) D.J. Middleton & $134.91 \pm 4.75$ & $0.38 \pm 0.42$ & $59.20 \pm 1.67$ & $4.36 \pm 0.34$ & 12.06 \\
\hline Urceola rosea (H. \& Arn.) D.J. Middleton & - & - & - & - & - \\
\hline Zingiber officinale Roscoe & $37.16 \pm 1.14$ & $0.78 \pm 1.11$ & $198.26 \pm 5.51$ & $18.29 \pm 1.70$ & 12.65 \\
\hline Ascobic acid & $88.00 \pm 2.54$ & $1.54 \pm 0.18$ & $72.20 \pm 0.30$ & $13.44 \pm 0.77$ & 11.69 \\
\hline \multirow[t]{2}{*}{ Trolox } & $12.94 \pm 0.20$ & $2.93 \pm 0.03$ & - & - & - \\
\hline & $18.80 \pm 0.56$ & $2.99 \pm 0.11$ & - & - & - \\
\hline
\end{tabular}


Table 2: Inhibition (\%) and $\mathrm{IC}_{50}$ values $(\mu \mathrm{g} / \mathrm{ml})$ of ethanol extract of Ya-hom Intajak and its $\mathrm{n}$-hexane, dichloromethane and $80 \%$ ethanol fractions on LDL oxidation

\begin{tabular}{|c|c|c|c|}
\hline Sample & $\begin{array}{l}\text { Concentration } \\
(\mu \mathrm{g} / \mathrm{ml})\end{array}$ & Inhibition (\%) & $I C_{50}$ \\
\hline Yahom formula extract & $\begin{array}{l}6.25 \\
3.13 \\
1.56 \\
0.78 \\
0.39\end{array}$ & $\begin{array}{c}72.85 \pm 4.16 \\
67.37 \pm 3.13 \\
51.73 \pm 5.78 \\
5.57 \pm 1.50 \\
2.30 \pm 0.81\end{array}$ & 2.43 \\
\hline Ethanol fraction & $\begin{array}{l}6.25 \\
3.13 \\
1.56 \\
0.78 \\
0.39\end{array}$ & $\begin{array}{r}72.92 \pm 1.80 \\
57.16 \pm 4.51 \\
38.51 \pm 4.42 \\
5.57 \pm 1.50 \\
4.93 \pm 0.37\end{array}$ & 2.76 \\
\hline $\begin{array}{l}\text { Dichloromethane } \\
\text { fraction }\end{array}$ & $\begin{array}{l}6.25 \\
3.13 \\
1.56 \\
0.78 \\
0.39\end{array}$ & $\begin{array}{l}77.61 \pm 3.10 \\
77.56 \pm 0.07 \\
67.82 \pm 0.04 \\
55.23 \pm 0.40 \\
27.61 \pm 0.40\end{array}$ & 0.82 \\
\hline $\mathrm{n}$-Hexane fraction & $\begin{array}{l}6.25 \\
3.13 \\
1.56 \\
0.78 \\
0.39\end{array}$ & $\begin{array}{l}72.86 \pm 3.56 \\
71.92 \pm 0.80 \\
57.30 \pm 0.24 \\
36.96 \pm 2.94 \\
17.25 \pm 0.81\end{array}$ & 1.47 \\
\hline Probucol & $\begin{array}{l}6.25 \\
3.13 \\
1.56 \\
0.78 \\
0.39\end{array}$ & $\begin{array}{l}76.32 \pm 0.01 \\
70.18 \pm 0.80 \\
59.53 \pm 1.81 \\
51.93 \pm 1.73 \\
39.88 \pm 2.57\end{array}$ & 0.75 \\
\hline
\end{tabular}

Other plants exhibiting strong DPPH scavenging activity were Caesalpinia sappan, Cinnamomum bejolghota and $C$. verum. The results indicate that the extracts of these plants contained compounds that were relatively strong scavengers of free radicals. The antioxidant effect is due to the ability of the compounds in the plants extracts to transfer electron or hydrogen atom to neutralize radicals of DPPH to form neutral DPPH molecules [20].

The ethanol extract of Ya-hom showed the highest antioxidant capacity $(1.12 \mathrm{mmol} \mathrm{Fe}(\mathrm{II}) / \mathrm{g})$ while its fractions exhibited lower activity. The FRAP values of the 47 plants varied from 0.18 to $2.77 \mathrm{mmol} \mathrm{Fe}(\mathrm{II}) / \mathrm{g}$ with a difference of 15 -fold between the lowest and highest activity. Among the plants tested, seven plants showed higher FRAP value than the whole Ya-hom formula and Caesalpinia sappan had the highest FRAP value (2.77 $\mathrm{mmol} \mathrm{Fe}(\mathrm{II}) / \mathrm{g})$ which was comparable to that of the positive control, ascorbic acid. C. sappan alcohol extract has been reported to exhibit $\mathrm{IC}_{50}$ values on DPPH and nitric oxide method comparable to those of ascorbic acid and rutin. Moreover, hematein, a compound isolated from C. sappan wood was able to reduce fatty streak lesion of cholesterol-fed rabbits and has a potential to be used as an anti-atherogenic agent [21]. Other plants with strong FRAP activity were Terminalia chebula, Cinnamomum bejolghota and $C$. verum.

The results showed that the methanol extracts of these plants contained high levels of phenolic contents. Among all the plant extracts, the highest TPC and TFC was observed in the extract of Terminalia chebula while the lowest TPC was in the extract of Nigella sativa and the lowest TF was in the extract of Myristica fragrans. Phenolic compounds have been reported to be the major contributor to the antioxidant activities of grain, vegetables and other botanical materials [18]. Flavonoid is one of the most important natural phenolics which some of them became to be widely known as potent antioxidants such as quercetin and rutin.

The extracts and its fractions showed significant antioxidant activity on LDL oxidation as at 6.25 $\mu \mathrm{g} / \mathrm{ml}$, all samples exhibited greater than $70 \%$ inhibition of LDL oxidation. The most active sample was dichloromethane fraction which showed an $\mathrm{IC}_{50}$ value $(0.82 \mu \mathrm{g} / \mathrm{ml})$ comparable to that of probucol, a potent inhibitor of coppercatalysed LDL peroxidation (Table 2). The results 
demonstrated that the extracts inhibited the copper-mediated oxidation of LDL in a dosedependent manner, as the concentration of the extract increased the percentage inhibition increased. The results indicate that the extract of Ya-hom contained compounds that are relatively strong inhibitors of LDL peroxidation. The antioxidant effect is due to the ability of the compounds in the plants extracts to chelate $\mathrm{Cu}^{2+}$ ion and thus may inhibit the initiation of LDL oxidation and free radical formation at the lipoprotein. The extracts may also form chelating complexes with transition metals to reduce their availability as catalysts for free radical generation [20].

\section{CONCLUSION}

This study indicates that the two types of antioxidant capacity measurements, DPPH and FRAP, of the plant extracts provide broadly similar order of antioxidant activity. The results imply that the antioxidants in these plants are capable of scavenging free radicals and reducing oxidants. The high correlation between the antioxidant and activities and their TPC and TF indicates that phenolic compounds are the major contributor of antioxidant capacities of these plants. The extract of Ya-hom Intajak and its fractions possesses significant antioxidant activity on LDL oxidation, indicating that the extract contained compounds that were relatively strong inhibitors of LDL peroxidation. The plants are valuable sources of natural antioxidants.

\section{ACKNOWLEDGEMENT}

The authors would like to acknowledge the Graduate Studies of Mahidol University Alumni Association, Thailand and the Ministry of Agriculture Malaysia for financial support (grant no. 05-01-02-SF1008).

\section{REFERENCES}

1. Heinecke JW. Lipoprotein oxidation in cardiovascular disease: chief culprit or innocent bystander. J Exp Med. 2006; 203: 813-816.

2. Rice-Evans CA, Miller NJ, Paganga G. Antioxidant properties of phenolic compounds. Trends Plant Sci. 1997; 2: 152-159.

3. Velioglu YS, Mazza G, Gao L, Oomah BD. Antioxidant activity and total phenolics in selected fruits, vegetables and grain products. J Agric Food Chem. 1998; 46: 4113-4117.

4. Odabasoglu F, Aslan A, Cakir A, Suleyman H, Karaqoz $Y$, Halici $M$, Bayir $Y$. Comparison of antioxidant activity and phenolic content of three lichen species. Phytother Res. 2004; 11: 938-941.

5. Hodzic Z, Pasalic H, Memisevic A, Srabovic M, Saletovic $M$, Poljakovic $M$. The Influence of total phenols content on antioxidant capacity in the whole grain extract. Eur J Sci Res. 2009; 3: 471-477.

6. Sirisangtrakul $W$, Sripanidkulchai $B$. Interference of Thai Traditional Medicine (Ya-hom Ampanthong) on hepatic cytochrome P-450 enzymes and pentobarbital-induced sleeping in mice. Pakistan $J$ Biol Sci. 2011; 14: 91-98.

7. Matangkasombat $O$. Pharmacological effects of Thai folk medicine (Ya-hom) on the blood pressure and cardiac function in man and experimental animal. Complete report submitted to the National Research Council of Thailand. 1974; 1-22.

8. Suvitayavat $W$, Tunglert $S$, Thirawarapan SS, Bunyapraphatsara N. Effects of Ya-hom on blood pressure in rats. J Ethnopharmacol. 2005; 97: 3-508.

9. Suvitayavat $W$, Tunglert $S$, Thirawarapan SS, Kitpati $C$, Bunyapraphatsara N. Actions of Ya-hom, a herbal drug combination, on isolated rat aortic ring and atrial contractions. Phytomedicine. 2005; 12: 561-569.

10. Na Pattaloong P, Sawasdimongkol K. Action of Thai traditional cardiotonic preparations (Ya-hom) on isolated rat atrium. Bull Depart Med Sc. 1995; 37: 271-288.

11. National Drug Committee. List of Herbal Medicine Product A.D. 2011, Agricultural Cooperative Federation Printing, Thailand.

12. Kordali S, Cakir A, Mavi A, Kilic H, Yildirim A. Screening of chemical composition and antifungal and antioxidant activities of the essential oils from three Turkish Artemisia species. J Agri Food Chem. 2005; 53: 1408-1416.

13. Benzie IFF, Szeto YT. Total antioxidant capacity of teas by the ferric reducing/antioxidant power assay. J Agri Food Chem. 1999; 47: 633-636.

14. Dillon SA, Burmi RS, Lowe GM, Billington D, Rahman $K$. Antioxidant properties of aged garlic extract: an in vitro study incorporating human low density lipoprotein. Life Sci. 2003; 72: 1583-1594

15. International Ethical Guidelines for Biomedical Research Involving Human Subjects. Prepared by the Council for International Organizations of Medical Sciences (CIOMS) in collaboration with the World Health Organization (WHO). Geneva, 2002. 64 pp. ISBN 92 90360755

16. Singleton VL, Orthofer R, Raventos RML. Analysis of total phenols and other oxidation substrates and antioxidants by means of Folin-Ciocalteu reagent. Meth Enzymol. 1999; 299: 152-178.

17. Meda A, Lamien CE, Romito M, Millogo J. Nacoulma OG. Determination of the total phenolic, flavonoid and proline contents in Burkina fasan honey, as well as their radical scavenging activity. Food Chem. 2005; 91: 571-577. 
18. Wong SP, Leong LP, Koh JHW. Antioxidant activities of aqueous extracts of selected plants. Food Chem. 2006; 99: 775-783.

19. Manosroi A, Jantrawut $P$, Akihisa T, Manosri W, Manosri $J$. In vitro anti-aging activities of Terminalia chebula gall extract. Pharm Biol. 2010; 48: 469-481.
20. Yu L, Zhou K, Parry JW. Inhibitory effects of wheat bran extracts on human $L D L$ oxidation and free radicals. LWT-Food Sci Technol. 2005; 38: 463-470.

21. Badami S, Moorkoth S, Rai SR, Kanna E, Bhojraj S. Antioxidant Activity of Caesalpinia sappan Heartwood. Biol Pharm Bull. 2003; 26: 1534-1537. 